\title{
Ex vivo Bone Models and Their Potential in Preclinical Evaluation
}

\author{
E. E. A. Cramer $^{1} \cdot$ K. Ito ${ }^{1} \cdot$ S. Hofmann ${ }^{1}$
}

Accepted: 16 December 2020 / Published online: 11 January 2021

(C) The Author(s) 2021

\begin{abstract}
Purpose of Review Novel therapies for damaged and diseased bone are being developed in a preclinical testing process consisting of in vitro cell experiments followed by in vivo animal studies. The in vitro results are often not representative of the results observed in vivo. This could be caused by the complexity of the natural bone environment that is missing in vitro. Ex vivo bone explant cultures provide a model in which cells are preserved in their native three-dimensional environment. Herein, it is aimed to review the current status of bone explant culture models in relation to their potential in complementing the preclinical evaluation process with specific attention paid to the incorporation of mechanical loading within ex vivo culture systems.

Recent Findings Bone explant cultures are often performed with physiologically less relevant bone, immature bone, and explants derived from rodents, which complicates translatability into clinical practice. Mature bone explants encounter difficulties with maintaining viability, especially in static culture. The integration of mechanical stimuli was able to extend the lifespan of explants and to induce new bone formation.

Summary Bone explant cultures provide unique platforms for bone research and mechanical loading was demonstrated to be an important component in achieving osteogenesis ex vivo. However, more research is needed to establish a representative, reliable, and reproducible bone explant culture system that includes both components of bone remodeling, i.e., formation and resorption, in order to bridge the gap between in vitro and in vivo research in preclinical testing.
\end{abstract}

Keywords Bone explants $\cdot$ Ex vivo bone model $\cdot$ Mechanical loading $\cdot$ Osteocytes $\cdot$ Bone formation $\cdot$ Bone resorption

\section{Introduction}

Bone is a dynamic tissue that constantly adapts its architecture to the environment. This process is controlled by the interactive relationship between osteocytes, osteoblasts, and osteoclasts [1]. Osteoblasts are the bone-forming cells that deposit unmineralized matrix, called osteoid, while osteoclasts are responsible for resorption of bone matrix [2]. Osteocytes are embedded in the mineralized matrix and able to sense changes in their environment, which they transduce to other cells, including osteoclasts and osteoblasts [3].

This article is part of the Topical Collection on Skeletal Biology and Regulation

S. Hofmann

S.Hofmann@tue.nl

1 Orthopaedic Biomechanics, Department of Biomedical Engineering and Institute of Complex Molecular Systems, Eindhoven University of Technology, P.O. Box 513, 5600 MB Eindhoven, the Netherlands
With aging, the adaptive response is reduced, creating an imbalance between bone formation and resorption. This abnormal bone remodeling is a primary cause of bone diseases, including osteoporosis [4]. New anabolic and anticatabolic therapies for osteoporosis are being developed and evaluated in preclinical testing processes, which depend heavily on animal models $[5,6]$. In vivo experimentation is not only used to screen novel biochemical factors for metabolic bone diseases, it is also used to investigate bone development and growth, examine novel bone substitutes, and study impaired bone healing caused by clinical conditions, such as fracture non-unions, diabetes, and metastatic tumors [7-10]. Animal research is complex, expensive, time-consuming, and requires large sample numbers to show relevant effects $[11,12]$. Therefore, in vivo testing is often preceded by in vitro studies as an initial evaluation of for example cytotoxicity, mechanism, and proliferative effect of novel therapies on bone cells [13, 14].

Since in vitro experiments are performed with standard culture vessels consisting of 2D single- or dual-cell cultures 
on tissue-culture plastic, they are simple and cost-effective. The complexity and relevance have advanced using $3 \mathrm{D}$ cell cultures on scaffolds or cell spheroids [15]. With excellent control over the culture conditions, such as cell number and differentiation, reproducible and high-throughput experiments can be generated [15]. However, the absence of the original extracellular matrix (ECM) and spatial arrangement as is seen in vivo can lead to changes in cell morphology and protein expression, predominantly in $2 \mathrm{D}$ cultures $[6,16 \bullet]$. Consequently, the outcomes of in vitro experiments are often not representative of what is observed in vivo, which challenges the translation into clinical practice [15, 17].

Explant cultures, also known as organ or ex vivo cultures, maintain or grow explanted tissue in vitro, thus providing a unique platform to study cells in their native ECM with preservation of cell-cell and cell-matrix interactions as found in vivo. Moreover, ex vivo systems simplify the complexities of in vivo animal experiments, for example with the absence of systemic factors, thereby providing a controlled experimental setting where biological or mechanical factors can be examined independently [16•]. This could lead to valuable insights needed to bridge the gap between in vitro and in vivo experimentation, while it also addresses ethical considerations concerning animal testing by reducing and refining animal studies $[13,17,18]$.

Several explant models in bone research have been established and detailed descriptions of methodologies have been outlined [19]. The purpose of this article is to review the current status of the use of ex vivo culture systems and discuss challenges that need to be overcome in order to create representative, reliable, and reproducible model systems for bone explant culture. Special attention will be paid to the incorporation of mechanical loading as it is an essential factor in the bone environment [3]. Together, this will give insight into the potential of ex vivo bone models to become part of the preclinical testing process between simple in vitro testing and complex in vivo experimentation (Fig. 1).

\section{Mechanical Loading in Ex Vivo Bone Model Systems}

Mechanical loading plays an important role in maintaining bone mass and can evoke changes in bone structure to better resist the loading [20]. Bone explant cultures are of great interest to investigate the effects of mechanical loading, because they provide a unique controlled environment to independently examine the influence of mechanical stimuli. Table 1 provides a detailed overview of studies involving mechanical loading in ex vivo bone cultures categorized by type of mechanical stimulus and how the mechanical loading influenced the outcome.

In the human body, bones experience differences in the type and level of mechanical stimuli, which include compression and perfusion induced strain. Various methods have been established to incorporate these different types of mechanical stimuli into bone explant culture systems. Perfusion systems were employed to generate load-induced strain leading to fluid flow within bone explants, thereby providing a mechanical stimulus with the additional advantage of improving nutrient delivery and waste removal [57]. Simple systems specifically designed to apply compressive forces to whole embryonic bones, which cause direct deformations of bone matrix, were used to characterize the early osteocyte's response to loading $[22,25,26,57]$. The combination of perfusion and compression, which is of greater physiological relevance for explants of weight-bearing bones, was included in advanced culture systems and allowed longer ex vivo culture periods [16, 32]. The combination of mechanical stimuli was further advanced into a platform, called Zetos, able to apply compressive forces onto trabecular bone cores with high precision under constant perfusion [58]. The compressive forces could be applied in a variety of different wave forms and frequencies to simulate walking or jumping for example, while also having the ability to measure mechanical properties, such as stiffness, in real time [58]. A different type of bioreactor system combined perfusion with low magnitude, high-frequency vibrations to evoke shear stresses within bone explants without associated deformations in the bone matrix $[47,48]$. The absence of
Fig. 1 Traditionally, the development process for novel therapies related to bone starts with preclinical testing, consisting of in vitro experimentation and in vivo studies in animal models, followed by different phases of clinical trials in humans. Ex vivo models could potentially complement the pipeline of development when positioned between in vitro and in vivo testing. Image created with Biorender.com

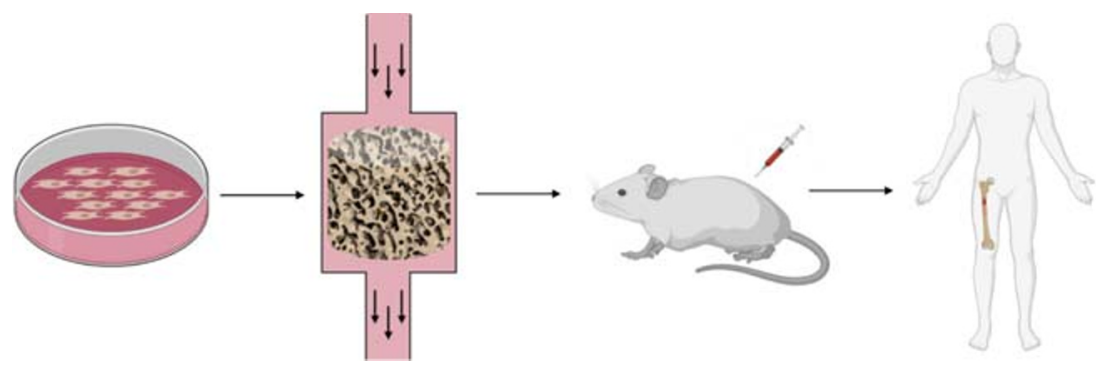

In vitro Ex vivo In vivo 
Table 1 Overview of studies involving mechanical loading in ex vivo bone cultures, listed by type of mechanical stimulus, species, origin of bone, type of explant, the presence of bone marrow experimental duration, and outcome (loaded vs. non-loaded samples)

\begin{tabular}{|c|c|c|c|c|c|c|c|}
\hline $\begin{array}{l}\text { Type of mechanical } \\
\text { stimulus }\end{array}$ & Species & $\begin{array}{l}\text { Origin of } \\
\text { bone }\end{array}$ & $\begin{array}{l}\text { Type of } \\
\text { explant } \\
\text { specimen }\end{array}$ & $\begin{array}{l}\text { Bone } \\
\text { marrow }\end{array}$ & $\begin{array}{l}\text { Culture } \\
\text { duration }\end{array}$ & Outcome & References \\
\hline \multirow[t]{4}{*}{ Perfusion } & Rat & Femur & $\begin{array}{l}\text { Bone shaft } \\
\text { and } \\
\text { condyles }\end{array}$ & & 14 days & $\begin{array}{l}\text { Loading enhanced preservation of osteocyte } \\
\text { viability }\end{array}$ & {$[21]$} \\
\hline & Mouse & Femur & $\begin{array}{l}\text { Whole } \\
\text { femur }\end{array}$ & + & $3 \mathrm{~h}$ & $\begin{array}{l}\mathrm{Ca}^{2+} \text { signaling of osteocytes in response to } \\
\text { mechanical signals }\end{array}$ & {$[22]$} \\
\hline & Chick & $\begin{array}{l}\text { Calvaria } \\
\text { (embry- } \\
\text { onic) }\end{array}$ & $\begin{array}{l}\text { Rectangular } \\
\text { segment }\end{array}$ & & $1 \mathrm{~h}$ & $\begin{array}{l}\text { Fluid flow increased cell response rate observed } \\
\text { from } \mathrm{Ca}^{2+} \text { dynamics }\end{array}$ & {$[23]$} \\
\hline & Human & Femur & $\begin{array}{l}\text { Complete } \\
\text { femoral } \\
\text { head }\end{array}$ & + & $12 \mathrm{~h}$ & $\begin{array}{l}\text { Preservation of cell viability by perfusion through } \\
\text { vasculature }\end{array}$ & {$[24]$} \\
\hline \multirow[t]{6}{*}{ Compression } & Chick & $\begin{array}{l}\text { Tibiotarsi } \\
\text { (embry- } \\
\text { onic) }\end{array}$ & Bone shaft & - & 2 days & $\begin{array}{l}\text { Increase in G6PD expression and RNA synthesis in } \\
\text { loaded samples }\end{array}$ & {$[25]$} \\
\hline & Rat & Ulna & Bone shaft & - & $24 \mathrm{~h}$ & $\begin{array}{l}\mathrm{PGI}_{2}, \mathrm{PGE}_{2} \text { and loading evoke an immediate } \\
\text { release of G6PD }\end{array}$ & {$[26]$} \\
\hline & Rat & $\begin{array}{l}\text { Ulna, } \\
\text { Calvaria }\end{array}$ & $\begin{array}{l}\text { Bone shaft }+ \\
\text { rectangu- } \\
\text { lar } \\
\text { segment }\end{array}$ & - & $6 \mathrm{~h}$ & $\begin{array}{l}\text { Release of } \mathrm{PGI}_{2} \text { and } \mathrm{PGE}_{2} \text {, upregulation of G6PD } \\
\text { upon loading in ulnae not in calvaria }\end{array}$ & {$[27]$} \\
\hline & Rat & Metatarsal & Bone shaft & + & $48 \mathrm{~h}$ & Greater osteocyte viability in loaded samples & {$[28]$} \\
\hline & Mouse & Tibia & Whole tibia & + & $\begin{aligned} 48 \mathrm{~h} \\
3 \mathrm{~h}\end{aligned}$ & $\begin{array}{l}\text { Intracellular } \mathrm{Ca}^{2+} \text { oscillations in osteocytes in } \\
\text { response to load and this diminished with age }\end{array}$ & [29], [30] \\
\hline & Mouse & Fibula & Whole fibula & + & $48 \mathrm{~h}$ & $\begin{array}{l}\text { Osteocytes in larger lacunae responded stronger to } \\
\text { loading }\end{array}$ & {$[31]$} \\
\hline \multirow[t]{3}{*}{ Perfusion + compression } & Canine & Femur & $\begin{array}{l}\text { Trabecular } \\
\text { bone core }\end{array}$ & - & $24 \mathrm{~h}$ & $\begin{array}{l}\text { Early response to loading by release of } \mathrm{PGE}_{2} \text { and } \\
\mathrm{PGI}_{2} \text { and upregulation of G6PD }\end{array}$ & {$[32],[33]$} \\
\hline & Bovine & (meta)tarsals & $\begin{array}{l}\text { Trabecular } \\
\text { bone core }\end{array}$ & - & 28 days & $\begin{array}{l}\text { Preservation of osteocyte viability in loaded } \\
\text { samples, osteocyte-osteoblast communication } \\
\text { visualized }\end{array}$ & {$[16 \bullet]$} \\
\hline & Rabbit & Femur & $\begin{array}{l}\text { Trabecular } \\
\text { bone core }\end{array}$ & + & 21 days & $\begin{array}{l}\text { Osteoid formation, upregulation of osteogenic } \\
\text { proteins and genes upon loading }\end{array}$ & {$[34]$} \\
\hline \multirow[t]{9}{*}{ Zetos system } & $\begin{array}{l}\text { Ovine, } \\
\text { Bovi- } \\
\text { ne, } \\
\text { Hum- } \\
\text { an }\end{array}$ & $\begin{array}{l}\text { Femur, } \\
\text { metacarp- } \\
\text { al, femur }\end{array}$ & $\begin{array}{l}\text { Trabecular } \\
\text { bone core }\end{array}$ & + & $3 \mathrm{~h}$ & $\begin{array}{l}\text { Optimized preparation for ovine, bovine and } \\
\text { human trabecular bone cores }\end{array}$ & {$[35]$} \\
\hline & Bovine & Sternum & $\begin{array}{l}\text { Trabecular } \\
\text { bone core }\end{array}$ & + & 21 days & $\begin{array}{l}\text { Elastic modulus increased when samples were } \\
\text { loaded. Big ET1 + load increased bone } \\
\text { formation }\end{array}$ & {$[36],[37]$} \\
\hline & Bovine & Sternum & $\begin{array}{l}\text { Trabecular } \\
\text { bone core }\end{array}$ & - & 18 days & $\begin{array}{l}\text { Exogenously added sclerostin inhibited the } \\
\text { increase in stiffness upon loading }\end{array}$ & {$[38]$} \\
\hline & Bovine & $\begin{array}{l}\text { Ulna, } \\
\text { Sternum }\end{array}$ & $\begin{array}{l}\text { Trabecular } \\
\text { bone core }\end{array}$ & + & 21 days & $\begin{array}{l}\text { Increased osteoblast activity and osteogenic } \\
\text { response in loaded groups }\end{array}$ & {$[39 \bullet \bullet]$} \\
\hline & Bovine & Ulna & $\begin{array}{l}\text { Trabecular } \\
\text { bone core }\end{array}$ & + & 26 days & $\begin{array}{l}\text { Different intensities of loading resulted in different } \\
\text { amounts of osteoid deposition }\end{array}$ & {$[40]$} \\
\hline & Bovine & $\begin{array}{l}\text { Ulna, } \\
\text { Sternum }\end{array}$ & $\begin{array}{l}\text { Trabecular } \\
\text { bone core }\end{array}$ & + & 21 days & $\begin{array}{l}\text { Scanning acoustic microscopy can be used to } \\
\text { assess changes in microelastic properties }\end{array}$ & {$[41]$} \\
\hline & Ovine & Vertebra & $\begin{array}{l}\text { Trabecular } \\
\text { bone core }\end{array}$ & + & 21 days & $\begin{array}{l}\text { Shear stress in loaded samples was determined with } \\
\text { computational modeling }\end{array}$ & {$[42 \bullet \bullet$} \\
\hline & Human & Femur & $\begin{array}{l}\text { Trabecular } \\
\text { bone core }\end{array}$ & + & 14 days & TGFß3 + load enhanced osteocyte survival & {$[43]$} \\
\hline & Human & Femur & $\begin{array}{l}\text { Trabecular } \\
\text { bone core }\end{array}$ & + & 27 days & $\begin{array}{l}\text { Increased preservation of osteocyte viability when } \\
\text { loaded. Assessment of Zetos bioreactor for } \\
\text { suitability of bone substitute testing. }\end{array}$ & $\begin{array}{l}{[44 \cdot],[45]} \\
{[46]}\end{array}$ \\
\hline \multirow[t]{2}{*}{ Perfusion + vibration } & Ovine & Vertebra & $\begin{array}{l}\text { Trabecular } \\
\text { bone core }\end{array}$ & + & 19 days & $\begin{array}{l}\text { Mechanical loading influenced cilia expression of } \\
\text { marrow cells }\end{array}$ & {$[47]$} \\
\hline & Porcine & Vertebra & $\begin{array}{l}\text { Trabecular } \\
\text { bone core }\end{array}$ & + & 19 days & $\begin{array}{l}\text { Increase in bone formation upon stimulation of } \\
\text { bone marrow }\end{array}$ & {$[48]$} \\
\hline
\end{tabular}


Table 1 (continued)

\begin{tabular}{|c|c|c|c|c|c|c|c|}
\hline $\begin{array}{l}\text { Type of mechanical } \\
\text { stimulus }\end{array}$ & Species & $\begin{array}{l}\text { Origin of } \\
\text { bone }\end{array}$ & $\begin{array}{l}\text { Type of } \\
\text { explant } \\
\text { specimen }\end{array}$ & $\begin{array}{l}\text { Bone } \\
\text { marrow }\end{array}$ & $\begin{array}{l}\text { Culture } \\
\text { duration }\end{array}$ & Outcome & References \\
\hline & Porcine & Vertebra & $\begin{array}{l}\text { Trabecular } \\
\text { bone core }\end{array}$ & + & 28 days & $\begin{array}{l}\text { Osteocytes were not responsible for increases in } \\
\text { bone formation upon mechanical loading }\end{array}$ & [49] \\
\hline \multirow[t]{2}{*}{ Hydrostatic pressure } & Bovine & Metacarpals & $\begin{array}{l}\text { Trabecular } \\
\text { bone core }\end{array}$ & - & 22 days & $\begin{array}{l}\text { Enhanced osteocyte viability and osteoid formation } \\
\text { within loaded samples }\end{array}$ & {$[50]$} \\
\hline & Chick & $\begin{array}{l}\text { Femur } \\
\text { (embry- } \\
\text { onic) }\end{array}$ & $\begin{array}{l}\text { Whole } \\
\text { femur }\end{array}$ & + & 14 days & Increased mineralization within loaded samples & {$[51]$} \\
\hline Stretch & Chick & Tibia & Bone slice & & $24 \mathrm{~h}$ & Increase in calcified area within loaded samples & {$[52]$} \\
\hline \multirow[t]{2}{*}{ Three-point bending } & Rat & Femur & $\begin{array}{l}\text { Whole } \\
\text { femur }\end{array}$ & + & 7 days & $\begin{array}{l}\text { Mechanical stimulation resulted in increased } \\
\text { stiffness }\end{array}$ & [53] \\
\hline & Rat & Femur & Bone slice & & 8 days & $\begin{array}{l}\text { Bone from aged rats showed diminished responses } \\
\text { to loading }\end{array}$ & {$[54],[55]$} \\
\hline Unloading & Rat & Tibia & $\begin{array}{l}\text { Proximal } \\
\text { epiphysis }\end{array}$ & + & 28 days & $\begin{array}{l}\text { Structural bone parameters and stiffness were } \\
\text { decreased in unloaded samples }\end{array}$ & {$[56]$} \\
\hline
\end{tabular}

$E T 1$ endothelin-1, G6PD glucose-6-phosphate dehydrogenase, $P G E_{2}$ prostaglandin E2, $P G I_{2}$ prostacyclin, $T G F \beta 3$ transforming growth factor beta 3 , "+" bone marrow present, “-“ bone marrow removed. No + or -, unclear whether bone marrow was present during culture

direct compression on the bone matrix was also realized in an ex vivo system utilizing cyclic hydrostatic pressure where gas surrounding the samples was compressed [50, 51]. Other, physiologically less relevant types of mechanical loading investigated in bone explant culture settings included static stretch and three-point bending [52-55].

\section{Influence of Mechanical Loading on Osteocytes in Bone Explants}

To study osteocyte function in their native environment without the influence of other cells, bone marrow, surface cells, and other soft tissue cells can be removed from bone explants [16, 19, 59-61]. The preservation of an intact lacunar-canalicular network allows for maintenance of mature osteocytes, which is a great advantage over current tissue engineered in vitro systems where this advanced osteocyte network is not yet achieved. This osteocyte model was used in static culture to study the effect of biochemical factors on osteocytes as well as to analyze the interaction between osteocytes and other cell types that were exogenously seeded [16, 50, 62-65]. However, mechanical loading appears to be an important factor for culture of marrow deprived bone explants, probably because of the role of osteocytes as mechanosensors of bone. Through culturing bone explants in perfusion bioreactors, osteocytes retained viability and function for 14 days, whereas most of the osteocytes died or disappeared from the lacunae in static culture with viable cells only found on the edges because they could be reached by diffusion [16, 21]. Also, the application of either cyclic hydrostatic pressure or compressive loading showed to enhance osteocyte viability $[28,50]$. When investigating the osteocyte response to mechanical loading, it was observed that the combination of perfusion and compression evoked an immediate release of prostaglandin $\mathrm{E} 2\left(\mathrm{PGE}_{2}\right)$ and prostacyclin $\left(\mathrm{PGI}_{2}\right)$ followed by an upregulation of G6PD activity [32, 33]. The upregulation of $\mathrm{PGI}_{2}$ was not observed when non-loadbearing calvarial tissue was subjected to loading [27]. More recent research reported that the early release of $\mathrm{PGE}_{2}$ by osteocytes was related to increased levels of bone formation after 4 weeks of culture when osteoblasts were seeded onto bone specimens [16, 66]. Ex vivo bone cultures were further used to investigate another early event in the cascade of mechanotransduction, a peak in intracellular calcium $\left(\mathrm{Ca}^{2+}\right)$. The culture system was designed to visualize, in real-time, $\mathrm{Ca}^{2+}$ dynamics in osteocytes in response to compressive loads $[29,30]$. Building on this work, a setting was created in which the effects of fluid flow on osteocytes could be studied in the absence of mechanical deformation of the matrix by directly applying fluid flow into the marrow cavity [22]. Upon mechanical stimulation through fluid flow, osteocytes displayed upregulation of the $\mathrm{Ca}^{2+}$ response $[22,23]$. Overall, the incorporation of mechanical loading into bone explant culture systems led to osteocyte responses, including increased osteocyte survival, $\mathrm{PGE}_{2}$ and $\mathrm{PGI}_{2}$ release, and $\mathrm{Ca}^{2+}$ dynamics, previously reported for in vivo and in vitro systems.

\section{Influence of Mechanical Loading on Bone Formation in Bone Explants}

Mechanotransduction includes osteocyte signaling to other bone cells, such as osteoblasts and osteoclasts, thereby coordinating matrix remodeling [29]. Instead of flushing out bone marrow to study osteocytes exclusively, bone marrow can be preserved to investigate bone formation and resorption 
processes [36, 38]. The maintenance of bone marrow provides cellular heterogeneity, including osteoclasts, osteoblasts, and their progenitors, necessary for bone remodeling [47]. The contributing role of marrow in the bone remodeling process was demonstrated within trabecular bone cores using an ex vivo perfusion system combined with vibrational stimuli [48]. A positive correlation between induced shear stress in the bone marrow and bone formation was found [48]. Since osteocytes were unaffected by this type of mechanical stimulation, the increased bone formation indicated that marrow cells are also mechanosensitive and play a role in bone remodeling [49]. Moreover, osteocytes are known to affect bone remodeling by expressing a range of proteins and cytokines [67], [68]. For bone explants in static cultures, presence of signaling molecules included in the bone formation and resorption pathways, such as sclerostin and RANKL, was demonstrated [68-71]. However, the influence of mechanical loading on the expression of these proteins and whether they have a direct effect on bone remodeling in bone explant cultures has to be investigated.

Using the Zetos bioreactor system, trabecular bone cores showed increased preservation of osteocyte viability and increased amounts of bone formation observed from upregulated osteoblast activity, osteoid deposition, trabecular thickening, and a higher Young's modulus, compared with unloaded samples [38-40, 44]. Analysis at multiple depths of the bone core displayed osteocyte viability throughout the thickness, suggesting that the combination of continuous perfusion and daily loading induced a fluid distribution that was able to reach the center of the bone explants [44•]. Survival of osteocytes in the core centers was further enhanced by the administration of TGFB3 [43]. Using the ability of the system to determine stiffness of the bone samples demonstrated that stiffness increased over time for samples subjected to daily loading $[36,40]$. The increased stiffness was found to be dependent on the magnitude of peak strain and related to osteoid thickness [40]. The Zetos system measured stiffness of the total sample, whereas scanning acoustic microscopy was utilized in a similar ex vivo setup to map spatial variations of acoustic impedance, which is related to tissue stiffness, within single trabeculae [41].

The incorporation of mechanical loading, especially the combination of perfusion with another type of loading, has shown to be able to extend culture periods (up to 4 weeks) and was associated with stronger osteogenic responses compared with static cultures $[16 \bullet, 36,39 \bullet \bullet, 44 \bullet \bullet, 49]$. This underlines the importance of bioreactors in addressing one of the challenges in bone explant culture, the limited lifespan [15]. Moreover, osteogenic responses of bone explants to biochemical factors were different when mechanical stimulation was included [26, 37, 43]. Therefore, the incorporation of mechanical stimuli is strongly suggested when examining the effects of biomaterials and drugs on bone explants, especially for long-term culture systems.

\section{Influence of Mechanical Loading on Bone Resorption in Bone Explants}

Mechanical stimuli are essential factors in the bone remodeling process which involves not only bone formation but also resorption [3]. One of the rare studies that investigated osteoclast activity and resorption upon mechanical loading demonstrated the presence of osteoclasts, no active resorption, and no response to mechanical loading [39•0]. However, the osteoclasts were still reactive when stimulated by retinoic acid. Bone resorption is known to increase in situations where mechanical loading is reduced or completely absent [3]. A constantly rotating bioreactor allowed culture of bone explants in an environment achieving near-weightlessness [56, 72]. After a 3-4-week culture, reduced levels of bone volume and mechanical properties were observed suggesting an increased resorption, although thorough analysis of osteoclast activity was not performed [56].

Up until now, studies involving mechanical loading in bone explant cultures showed a clear focus on achieving bone formation and neglecting osteoclast activity and resorption while both are key elements of bone remodeling in vivo. Consequently, culture medium is often supplemented with factors that stimulate osteoblasts in producing bone matrix, while osteoclasts are not stimulated and even might be suppressed. For static explant cultures, it was demonstrated that osteoclastogenesis could be induced by the bacterial factor LPS, parathyroid hormone, or pro-inflammatory cytokines, such as RANKL, MCSF, IL-6, and TNF- $\alpha$ [73, 74]. Therefore, more research is needed to provide osteoclasts with an environment that facilitates resorption within mechanically stimulated bone explant models in order to generate a model that comprises both elements of bone remodeling.

\section{Physiological Relevance of Bone Used in Explant Models}

\section{Immature Vs. Mature Bone}

Embryonic or neonatal bone is frequently used for bone explant cultures because it allows for long-term culture with cell viability being maintained for up to several months [75-77]. However, incomplete mineralization and lack of mature immune cells make immature bone not representative for clinical situations which most often are targeted by therapies [78]. The use of mature bone is recommended as a more relevant scenario in preclinical testing. However, its culture is challenging because the diffusion of nutrients is hampered by the thick calcified tissue and the fatty bone marrow, which causes cell death and matrix degradation in static cultures $[79,80]$. 


\section{Animal Bone Vs. Human Bone}

Therapeutics are predominantly developed for human applications, but bone tissue used in ex vivo testing often originates from animals, including rodents, canine, and bovine. Consequently, species-specific differences in macrostructure, microarchitecture, composition, and bone remodeling result in a lack of correlation between animal and human experimental outcomes [7, 81]. Rodent models for example, often used for ex vivo experimentation, have differences in bone composition, mechanical properties, and are missing the Haversian remodeling system, leading to a gap in translation of therapies from mice to human $[6,81,82]$. The use of bone tissue from larger animals is clinically more relevant with respect to size and with a similar lamellar structure relative to human bone [7]. In addition, bone explant material from large animals is usually obtained from slaughterhouse's left-over material, such as ovine femora and bovine metacarpals, thereby circumventing the complicated regulations for animal studies and extra costs for animal care [35]. However, there is no animal model with an identical bone structure and physiology $[7,82]$. Hence, responses to drugs, such as BMP-2 and bisphosphonates, demonstrated to be different in animals compared with humans $[6,14,83]$.

Research involving human bone can be performed using left-over material from autografting procedures $[61,63,68$, $69,84,85]$. Usually, these include small thin fragments $(\varnothing=1 \mathrm{~mm})$ obtained from non-load bearing bones and do not include the extensive structure of trabeculae [61]. This is an important point of consideration as non-load bearing flat bones, such as calvariae, show a different osteogenic response to mechanical loading compared with trabecular bone from long bones [27, 39••, 41]. The use of human bone cores in ex vivo culture models could remove obstacles experienced in translating outcomes from animal experimentation to human applications. Trabecular bone cores $(\varnothing=6-20 \mathrm{~mm}$, height $=4-7 \mathrm{~mm})$, obtained from femoral heads or tibia plateaus removed during replacement surgeries, demonstrated successful preservation of viability ex vivo, when cultured up to 4 weeks $[14,35$, $43,44 \cdot, 46,80,86,87]$. Notably, a recent study reported that an entire human femoral head could be kept viable for $12 \mathrm{~h}$ when culture medium was perfused through the remaining vasculature [24].

Taken together, human bone tissue would be ideal for ex vivo cultures in terms of physiological relevance, but it has major downsides regarding availability and variability. This hampers large scale testing, which is needed to reach statistical significance in preclinical experiments. Therefore, benefit could be taken from easier accessible large animal bone specimens, usually obtained from slaughterhouse material, to create high throughput experimentation in order to establish reproducible systems.

\section{Ex Vivo Models for Bone Diseases}

The use of human bone tissue is further complicated by the presence of underlying diseases and the difficulty to obtain healthy tissue to serve as control. Frequently, femoral heads originate from osteoporotic patients which might be on bone affecting medication. However, these diseased bones could also provide an opportunity to create a physiologically relevant osteoporotic explant model, which could be of great interest for preclinical drug testing. Also, research related to rheumatoid arthritis (RA), an inflammatory disease associated with bone destruction, could benefit from ex vivo human bone models when using small pieces of bone isolated from joints of RA patients [61, 68, 88, 89]. Cancer metastasis in bone could be simulated by co-culture of human bone fragments and human prostate or breast cancer cells leading to infiltration of malignant cells into the bone marrow cavities reflecting the bone metastatic niche [90-93]. Osteoarthritis is a disease that is characterized by cartilage degeneration as well as changes in the subchondral bone with a close interrelationship between osteoblasts, osteoclasts, and chondrocytes [94]. Therefore, a clinically relevant preclinical model for osteoarthritis would involve explant tissue consisting of articular cartilage and subchondral bone, the so-called osteochondral unit, which can be obtained from distal femoral condyles or femoral heads [95-97]. However, osteochondral cultures were primarily optimized to investigate cartilage regeneration without considering the optimal culture conditions for bone $[95,97$, 98]. Recently, a culture platform with two separated media compartments was established, which achieved a better reproduction of the in vivo situation because signaling between the cartilage and bone could only happen through the subchondral bone plate [99].

\section{Correlation to In Vivo Data}

In order to implement bone explant cultures as valuable platforms in preclinical testing, it would be desirable to have ex vivo osteogenic responses predictive of in vivo success. To examine the correlation between ex vivo outcomes and in vivo results, a multicenter analysis would be needed, such as the study of Hulsart-Billström and colleagues where in vitro and in vivo data of biomaterials for bone regeneration were compared and correlated using a scoring system [17]. Once enough data is available, such a thorough analysis should also be performed to investigate the correlation between ex vivo and in vivo studies.

A major issue in comparing and correlating ex vivo and in vivo outcomes is the typical length of the culture periods. Explant cultures have a duration of days to a few weeks associated with minor amounts of bone formation and resorption, while in vivo models take up several weeks to complete in 
small animals and multiple months for large animals accomplishing substantial changes $[100,101]$. To overcome this issue, it would be ideal to adapt the different culture periods by also having in vivo results at early timepoints. Relating outcomes to in vivo results is further complicated by the variation in analysis techniques used, impeding direct comparison because bone responses are evaluated at different levels [101].

A few articles reported results of ex vivo research followed by in vivo evaluation intending to relate the outcomes [70, 102, 103]. However, different types of bones, calvariae and femur, were used and analysis was only performed on mRNA and protein level. Another study demonstrated increased amounts of bone formation in mouse calvariae culture upon administration of an anabolic small molecule [104]. Consistent with the ex vivo findings, increased bone formation was observed in a defect in vivo [104]. However, care needs to be taken with interpreting comparable outcomes as mechanisms behind the observed effects could differ, because parameters present in vivo are missing ex vivo, such as mechanical loading, the immune system, and an inflammatory response. These are known to be involved in bone regeneration. In addition, the required dosage of biochemical factors administered might require attention as uptake and transport differ between ex vivo and in vivo situations because the vascular network is missing. Hence, it cannot be expected that ex vivo cultures represent all processes happening in vivo and it needs to be evaluated whether ex vivo systems are complex enough to represent certain in vivo processes before they can be utilized as preclinical testing models.

\section{Applications of Ex Vivo Models in Preclinical Testing}

With the preservation of cells in their native environment, bone explant cultures might be of added value for preclinical evaluation of novel therapies targeting diseased or damaged bone. To evaluate biomaterials, ex vivo bone defect models were established that comprised embryonic bones with a central segmental defect [105-108] and trabecular bone cores of mature bone with a defect created centrally [46, 86, 109]. Outcomes were limited to demonstrating osteocyte viability and cellular ingrowth from the bone into the material [86, 109]. Only one paper analyzed the osteogenic response in more depth by monitoring factors as $\mathrm{Ca}^{2+}$, ALP, and osteocalcin in the medium and showing new bone formation by incorporation of tetracycline which was released from the bone substitute [46]. These studies showed the first step in creating an ex vivo defect model, but further development is needed before standardized testing of bone substitutes can be achieved. Hence, an important component in fracture healing that is challenging to integrate ex vivo is the inflammatory response and associated hematoma formation because vascularization is lacking. This challenge was partly addressed by an ex vivo study utilizing a femoral defect model to implant hydrogels that released platelet-rich plasma, which contains many cytokines involved in bone regeneration and vascularization processes [110]. A different approach to address the vascularization problem included culturing of bone explants on the chick chorioallantoic membrane (CAM) [14, 107]. Invasion of human bone cores by CAM capillaries was realized and ECM deposition and mineralization was shown, although mainly caused by the infiltrated avian cells $[14,111]$.

For testing the potency of growth factors and small molecules for bone-related diseases, explants obtained from mouse calvarial bones are regularly used because it is a relatively simple and inexpensive model [62, 70, 78, 104, 112-124]. The addition of human prostate or breast cancer cells to mouse calvariae allowed investigating the effects of several potential cancer therapeutics [74, 125-133]. Physiologically more relevant bone explants derived from large animals or humans were seldomly used to investigate effects of exogenously added factors [37, 38, 84, 134].

\section{Challenges in Isolation, Culture, and Analysis of Bone Explants}

Currently, bone explant cultures can take up months to complete and are performed manually creating operator-dependent variability $[6,78]$. This leaves room for improvements on optimization of isolation procedures, standardization of culture conditions, and automation of analysis techniques.

\section{Preparation of Bone Explants}

When tissue is harvested, it suffers from hypoxia and mechanical stress leading to cell death and changes in cell behavior as well as formation of bone debris clumps as a direct result of drilling [35, 86]. Consequently, an adaptation period characterized by an increased release of intracellular enzymes into the culture medium was observed during the first 2-6 days of culture $[86,135,136]$. Optimization of isolation could focus on reducing stress on cells during harvesting which could possibly shorten or refine the adaptation period.

\section{Culture of Bone Explants}

No consensus is reached about which medium is optimal for which type of bone explant. This leads to a variety of different media supplemented with all kinds of factors, including bovine albumin, ascorbic acid, fetal calf serum, and dexamethasone [82]. Dexamethasone, frequently used for in vitro culture of osteogenic cells, showed to negatively affect osteocytes in bone explants $[62,64]$. Also, the use of serum supplementation is debatable, because it has batch-to-batch variation 
leading to a reduced reproducibility, but its presence has shown to extend culture periods significantly [19]. Moreover, supplementation of medium adds charged molecules to the culture which can lead to disturbances of streaming potentials in the lacuna-canalicular network [137]. Serum alternatives, for example chemically defined serum-free media or human platelet lysate, are recommended to be tested for bone explant culture to overcome the issues with serum supplementation [138]. Overall, more research is needed to determine the optimal nutritional requirements for bone explants which might lead to enhanced cell activities and an increased lifespan.

Improvements can also be made on bioreactor design and usage, in order to achieve large-scale ex vivo experimentation. Most of the bioreactors are custom-built devices developed to answer a specific research question and only allow accommodation of bone explants with a specific shape and size. Only the Zetos platform showed to a certain extent the potency for screening factors and biomaterials under physiologically relevant loading $[35,58]$. Furthermore, studies examining effects of different load intensities, waveforms, frequencies, or number of cycles are limited but needed to determine the ideal loading regime for bone explants to evoke an osteogenic response similar to in vivo.

\section{Analysis of Bone Explants}

Whole bone explants pose challenges in the application of standard evaluation techniques because of the calcified bone and the fatty marrow limits dye penetration into the tissue [80]. Therefore, evaluation is often limited to measurement of markers, such as LDH, ALP, and TRAP, in the medium, which only provides insight into total turnover. In order to obtain local information, techniques need to be adapted and optimized, for example by longer incubation times and lowering temperatures to decrease metabolic activity of cells during viability analysis [80].

Histology in the form of H\&E staining is generally performed to visualize bone matrix. However, decalcification of mature bone tissue is required, which complicates discrimination between old and newly formed matrix. The use of plastic embedding and advanced histological stains, such as Masson Golder stain, avoids decalcification and could be of interest to implement as standard in analysis of bone formation [35]. Where histological analyses show the status of bone at a specific point when the sample is sacrificed, techniques to evaluate bone formation over a period are preferred to reduce the needed sample size. Dynamic histomorphometry, which has already been used in ex vivo systems, allows for visualization and quantification of bone formation during culture by the administration of calcium binding fluorochromes at specific timepoints [44•].
Micro computed tomography $(\mu \mathrm{CT})$ imaging is integrated in general bone research but only occasionally in explant cultures. This technique has a high potential for bone explant cultures as was shown with the visualization of remodeling $[34,48,139,140]$. In addition, the combination of $\mu \mathrm{CT}$ and finite element modeling allowed quantification of local matrix strains and marrow stresses, used to demonstrate that values were in the range known to induce an osteogenic response [42, 48]. The use of computational models to simulate processes inside the bone under specific conditions could further assist in the interpretation of experimental outcomes.

Depending slightly on the research question, research involving bone formation or resorption within bone explants might benefit from a standardized analysis protocol that combines different evaluation techniques to get information about different stages of culture. This should include analysis of biomarkers in the medium as an indication of total tissue activity and histology, dynamic histomorphometry, and $\mu \mathrm{CT}$ imaging for local analysis. Moreover, these techniques are also used for animal testing and would therefore allow for easier correlation to in vivo outcomes [141, 142].

\section{Conclusion}

A representative, reliable, and reproducible ex vivo system to assess the potency of novel treatments for damaged or diseased bone has yet to be established. The creation of standardized advanced models is hampered by different drawbacks of bone explant cultures, including limited lifespan in static culture and the absence of osteoclast activity and resorption, especially for mechanically loaded explants. To overcome these challenges, future research should focus on the incorporation of mechanical loading through standardized bioreactors and finding optimal culture conditions to allow osteoblasts as well as osteoclasts to fulfill their actions within the remodeling process. Furthermore, cultures with physiologically relevant bone tissue, ideally from large animals or humans, with optimized procedures of isolation, culture, and analysis are needed to establish platforms that could complement the process of preclinical testing. Thanks to the preservation of physical and spatial complexity, bone explant cultures could improve translatability between in vitro and in vivo studies and favors our ethical responsibility to reduce, refine, and replace animal testing.

Acknowledgments We gratefully acknowledge the Gravitation Program "Materials Driven Regeneration", funded by the Netherlands Organization for Scientific Research (024.003.013), and from the European Research Council (ERC) under the European Union's Horizon 2020 research and innovation programme (Grant agreement No. 956875).

Code Availability Not applicable. 
Authors' Contributions E.C. and S.H. conceptualized the review, E.C. collected and sorted the literature and wrote the draft. E.C., S.H., and K.I. edited and reviewed the manuscript.

Data Availability Not applicable.

\section{Compliance with Ethical Standards}

Conflict of Interest The authors declare no conflict of interest.

Open Access This article is licensed under a Creative Commons Attribution 4.0 International License, which permits use, sharing, adaptation, distribution and reproduction in any medium or format, as long as you give appropriate credit to the original author(s) and the source, provide a link to the Creative Commons licence, and indicate if changes were made. The images or other third party material in this article are included in the article's Creative Commons licence, unless indicated otherwise in a credit line to the material. If material is not included in the article's Creative Commons licence and your intended use is not permitted by statutory regulation or exceeds the permitted use, you will need to obtain permission directly from the copyright holder. To view a copy of this licence, visit http://creativecommons.org/licenses/by/4.0/.

\section{References}

Papers of particular interest, published recently, have been highlighted as:

- Of importance

•. Of major importance

1. Buck DW, Dumanian GA. Bone biology and physiology: part I. the fundamentals. Plast Reconstr Surg. Jun. 2012;129(6):1314 20.

2. Clarke B. Normal bone anatomy and physiology. Clinical journal of the American Society of Nephrology : CJASN. 2008;3(Suppl 3):S131.

3. Robling AG, Castillo AB, Turner CH. Biomechanical and molecular regulation of bone remodeling. Annu Rev Biomed Eng. Aug. 2006;8(1):455-98.

4. Raisz LG. Pathogenesis of osteoporosis: concepts, conflicts, and prospects. J Clin Investig. Dec. 2005;115(12):3318-25.

5. Bonjour JP, Ammann P, Rizzoli R. Importance of preclinical studies in the development of drugs for treatment of osteoporosis: a review related to the $1998 \mathrm{WHO}$ guidelines. Osteoporosis Int. 1999;9(5) Springer:379-93.

6. Sieberath A, della Bella E, Ferreira AM, Gentile P, Eglin D, Dalgarno K. A comparison of osteoblast and osteoclast in vitro co-culture models and their translation for preclinical drug testing applications. Int J Mol Sci. 2020;21(3).

7. Pearce A, Richards R, Milz S, Schneider E, Pearce S. Animal models for implant biomaterial research in bone: a review. Eur Cells Mater. 2007;13:1-10.

8. Colombo JS, Balani D, Sloan AJ, Crean SJ, Okazaki J, Waddington RJ. Delayed osteoblast differentiation and altered inflammatory response around implants placed in incisor sockets of type 2 diabetic rats. Clin Oral Implants Res. 2011;22(6):57886.

9. McGovern JA, Griffin M, Hutmacher DW. Animal models for bone tissue engineering and modelling disease. DMM Disease Models and Mechanisms. 2018;11(4)
10. Li Y, Chen SK, Li L, Qin L, Wang XL, Lai YX. Bone defect animal models for testing efficacy of bone substitute biomaterials. J Orthopaedic Transl. 2015;3(3):95-104.

11. Mills LA, Simpson AHRW. In vivo models of bone repair. The Journal of Bone and Joint Surgery British. Jul. 2012;94-B(7):86574.

12. Auer JA, et al. Refining animal models in fracture research: Seeking consensus in optimising both animal welfare and scientific validity for appropriate biomedical use. BMC Musculoskel Disord. 2007;8(72).

13. Doke SK, Dhawale SC. Alternatives to animal testing: a review. Saudi Pharm J. 2015;23(3):223-9.

14. Moreno-Jiménez I, et al. The chorioallantoic membrane (CAM) assay for the study of human bone regeneration: a refinement animal model for tissue engineering. Scientific Reports. 2016;6.

15. Peroglio M, Gaspar D, Zeugolis DI, Alini M. Relevance of bioreactors and whole tissue cultures for the translation of new therapies to humans. J Orthop Res. 2018;36(1):10-21.

16. Chan ME, et al. A trabecular bone explant model of osteocyteosteoblast co-culture for bone mechanobiology. Cellular and molecular bioengineering. 2009;2(3):405 This study indicates the potential of bone explant cultures to study osteocytes in their native environment.

17. Hulsart-Billström $\mathrm{G}$, et al. A surprisingly poor correlation between in vitro and in vivo testing of biomaterials for bone regeneration: results of a multicentre analysis. European Cells and Materials. May 2016;31:312-22

18. Russell W, Burch R. The principle of humane experimental technique. Londen: Methuen; 1959.

19. Marino S, Staines KA, Brown G, Howard-Jones RA, Adamczyk M. Models of ex vivo explant cultures: applications in bone research. BoneKEy reports. 2016;5:818.

20. Klein-Nulend J, Bacabac RG, Bakker AD. Mechanical loading and how it affects bone cells: the role of the osteocyte cytoskeleton in maintaining our skeleton. European Cells and Materials. 2012;24:278-91.

21. Davidson EH, et al. Flow perfusion maintains ex vivo bone viability: a novel model for bone biology research. J Tissue Eng Regen Med. 2012;6(10):769-76.

22. Hu M, Tian GW, Gibbons DE, Jiao J, Qin YX. Dynamic fluid flow induced mechanobiological modulation of in situ osteocyte calcium oscillations. Arch Biochem Biophys. 2015;579:55-61.

23. Ishihara $\mathrm{Y}$, et al. Ex vivo real-time observation of $\mathrm{Ca} 2+$ signaling in living bone in response to shear stress applied on the bone surface. Bone. 2013;53(1):204-15.

24. Swarup A, Weidner H, Duncan R, Nohe A. The preservation of bone cell viability in a human femoral head through a perfusion bioreactor. Materials. 2018;11(7).

25. Dallas SL, Zaman G, Pead MJ, Lanyon LE. Early strain-related changes in cultured embryonic chick tibiotarsi parallel those associated with adaptive modeling in vivo. J Bone Miner Res. 1993;8(3):251-9.

26. Cheng MZ, Zaman G, Lanyon LE. Estrogen enhances the stimulation of bone collagen synthesis by loading and exogenous prostacyclin, but not prostaglandin E2, in organ cultures of rat ulnae. J Bone Miner Res. 1994;9(6):805-16.

27. Rawlinson SCF, Mosley JR, Suswillo RFL, Pitsillides AA, Lanyon LE. Calvarial and limb bone cells in organ and monolayer culture do not show the same early responses to dynamic mechanical strain. J Bone Miner Res. 1995;10(8):1225-32.

28. Lozupone E, Palumbo C, Favia A, Ferretti M, Palazzini S, Cantatore FP. Intermittent compressive load stimulates osteogenesis and improves osteocyte viability in bones cultured in vitro. Clin Rheumatol. 1996;15(6):563-72. 
29. Jing D, et al. In situ intracellular calcium oscillations in osteocytes in intact mouse long bones under dynamic mechanical loading. FASEB J. 2014;28(4):1582-92.

30. Morrell AE, Robinson ST, Silva MJ, Guo XE. Mechanosensitive $\mathrm{Ca} 2+$ signaling and coordination is diminished in osteocytes of aged mice during ex vivo tibial loading. Connect Tissue Res. Jul. 2020;61(3-4):389-98.

31. Hemmatian $\mathrm{H}$, et al. Mechanical loading differentially affects osteocytes in fibulae from lactating mice compared to osteocytes in virgin mice: possible role for Lacuna size. Calcif Tissue Int. 2018;103(6):675-85.

32. Haj AJE, Minter SL, Rawlinson SCF, Suswillo R, Lanyon LE. Cellular responses to mechanical loading in vitro. J Bone Miner Res. 1990;5(9):923-32.

33. Rawlinson SCF, El-Haj AJ, Minter SL, Tavares IA, Bennett A, Lanyon LE. Loading-related increases in prostaglandin production in cores of adult canine cancellous bone in vitro: a role for prostacyclin in adaptive bone remodeling? J Bone Miner Res. 1991;6(12):1345-51.

34. Ming WZ, et al. Bone formation in rabbit cancellous bone explant culture model is enhanced by mechanical load. BioMedical Engineering Online. 2013;12(1):35.

35. Davies C, et al. Mechanically loaded ex vivo bone culture system 'Zetos': systems and culture preparation. European Cells and Materials. 2006;11:57-75.

36. Vivanco J, Garcia S, Ploeg HL, Alvarez G, Cullen D, Smith EL. Apparent elastic modulus of ex vivo trabecular bovine bone increases with dynamic loading. Proc Inst Mech Eng H J Eng Med. 2013;227(8):904-12.

37. Meyer LA, et al. Combined exposure to big endothelin-and mechanical loading in bovine sternal cores promotes osteogenesis. Bone. 2016;85:115-22.

38. Kogawa M, et al. Recombinant sclerostin antagonizes effects of ex vivo mechanical loading in trabecular bone and increases osteocyte lacunar size. Am J Phys Cell Phys. 2018;314(1):C53-61.

39.• David V, et al. Ex vivo bone formation in bovine trabecular bone cultured in a dynamic 3D bioreactor is enhanced by compressive mechanical strain. Tissue engineering. Part A. 2008;14(1):117-26 This study is of importance because it used various analysis methods to assess both bone formation and resorption on multiple levels within a mechanically loaded bone explant.

40. Endres S, Kratz M, Wunsch S, Jones DB. Zetos: a culture loading system for trabecular bone. Investigation of different loading signal intensities on bovine bone cylinders. Journal of Musculoskeletal Neuronal Interactions. 2009;9(3):173-83.

41. Rupin F, et al. Adaptive remodeling of trabecular bone core cultured in 3-D bioreactor providing cyclic loading: an acoustic microscopy study. Ultrasound Med Biol. 2010;36(6):999-1007.

42.• Birmingham E, Niebur GL, McNamara LM, McHugh PE. An experimental and computational investigation of bone formation in mechanically loaded trabecular bone explants. Annals of Biomedical Engineering. 2016;44(4):1191-203 This study demonstrates the potential of $\mu \mathrm{CT}$ in combination with computational modeling to assess bone remodeling and to calculate the local values of stress and strain in bone explant cultures.

43. Simpson AE, et al. TGF $\beta_{3}$ and loading increases osteocyte survival in human cancellous bone cultured ex vivo. Cell Biochem Funct. Jan. 2009;27(1):23-9.

44. Mann V, Huber C, Kogianni G, Jones D, Noble B. The influence of mechanical stimulation on osteocyte apoptosis and bone viability in human trabecular bone. Journal of Musculoskeletal Neuronal Interactions. 2006;6(4):408-17 This study is of importance because of the capability to preserve cell viability in human bone associated with bone formation during a 27-day culture period.
45. Richards RG, Simpson AE, Jaehn K, Furlong PI, Stoddart MJ. Establishing a 3D ex vivo culture system for investigations of bone metabolism and biomaterial interactions. ALTEX. 2007;24(Special issue):56-9.

46. Schnieders J, Gbureck U, Germershaus O, Kratz M, Jones DB, Kissel T. Ex vivo human trabecular bone model for biocompatibility evaluation of calcium phosphate composites modified with spray dried biodegradable microspheres. Advanced Healthcare Materials. 2013;2(10):1361-9.

47. Coughlin TR, et al. Primary cilia expression in bone marrow in response to mechanical stimulation in explant bioreactor culture. European cells \& materials. 2016;32:111-22.

48. Birmingham E, et al. Mechanical stimulation of bone marrow in situ induces bone formation in trabecular explants. Ann Biomed Eng. 2015;43(4):1036-50.

49. Curtis KJ, Coughlin TR, Mason DE, Boerckel JD, Niebur GL. Bone marrow mechanotransduction in porcine explants alters kinase activation and enhances trabecular bone formation in the absence of osteocyte signaling. Bone. 2018;107:78-87.

50. Takai E, Mauck RL, Hung CT, Guo XE. Osteocyte viability and regulation of osteoblast function in a $3 \mathrm{D}$ trabecular bone explant under dynamic hydrostatic pressure. J Bone Miner Res. 2004;19(9):1403-10.

51. Henstock JR, Rotherham M, Rose JB, el Haj AJ. Cyclic hydrostatic pressure stimulates enhanced bone development in the foetal chick femur in vitro. Bone. 2013;53(2):468-77.

52. Maeda E, Ichikawa K, Murase K, Nagayama K, Matsumoto T. Ex-vivo observation of calcification process in chick tibia slice: augmented calcification along collagen fiber orientation in specimens subjected to static stretch. J Biomech. 2018;78:94-101.

53. Saunders MM, Simmerman LA, Reed GL, Sharkey NA, Taylor AF. Biomimetic bone mechanotransduction modeling in neonatal rat femur organ cultures: structural verification of proof of concept. Biomech Model Mechanobiol. 2010;9(5):539-50.

54. Hoffler CE, Hankenson KD, Miller JD, Bilkhu SK, Goldstein SA. Novel explant model to study mechanotransduction and cell-cell communication. J Orthop Res. 2006;24(8):1687-98.

55. Joiner DM, Tayim RJ, McElderry JD, Morris MD, Goldstein SA. Aged male rats regenerate cortical bone with reduced osteocyte density and reduced secretion of nitric oxide after mechanical stimulation. Calcif Tissue Int. 2014;94(5):484-94.

56. Cosmi F, Steimberg N, Mazzoleni G. A mesoscale study of the degradation of bone structural properties in modeled microgravity conditions. J Mech Behav Biomed Mater. 2015;44:61-70.

57. Lanyon LE. Control of bone architecture by functional load bearing. Journal of Bone and Mineral Research. 1992;7(2 S):S369-75.

58. Jones DB, Broeckmann E, Pohl T, Smith EL. Development of a mechanical testing and loading system for trabecular bone studies for long term culture. European Cells and Materials. 2003;5:4860 .

59. Bellido T, Delgado-Calle J. Ex vivo organ cultures as models to study bone biology. JBMR Plus. 2020;4(3).

60. Sakaguchi Y, Sekiya I, Yagishita K, Ichinose S, Shinomiya K, Muneta T. Suspended cells from trabecular bone by collagenase digestion become virtually identical to mesenchymal stem cells obtained from marrow aspirates. Blood. 2004;104(9):2728-35.

61. Ito N, et al. Regulation of FGF23 expression in IDG-SW3 osteocytes and human bone by pro-inflammatory stimuli. Mol Cell Endocrinol. 2015;399:208-18.

62. Gao J, et al. Glucocorticoid impairs cell-cell communication by autophagymediated degradation of connexin 43 in osteocytes. Oncotarget. 2016;7(19):26966-78.

63. Li F, Cain JD, Tombran-Tink J, Niyibizi C. Pigment epitheliumderived factor (PEDF) reduced expression and synthesis of SOST/sclerostin in bone explant cultures: implication of PEDF- 
osteocyte gene regulation in vivo. J Bone Miner Metab. 2019;37(5):773-9.

64. Gu G, Mulari M, Peng Z, Hentunen TA, Väänänen HK. Death of osteocytes turns off the inhibition of osteoclasts and triggers local bone resorption. Biochem Biophys Res Commun. 2005;335(4): 1095-101.

65. Shimizu H, Sakamoto M, Sakamoto S. Bone resorption by isolated osteoclasts in living versus devitalized bone: differences in mode and extent and the effects of human recombinant tissue inhibitor of metalloproteinases. J Bone Miner Res. 1990;5(4): 411-8.

66. Bancroft GN, et al. Fluid flow increases mineralized matrix deposition in 3D perfusion culture of marrow stromal osteoblasts in a dose-dependent manner. Proc Natl Acad Sci U S A. 2002;99(20): 12600-5.

67. Dallas SL, Prideaux M, Bonewald LF. The osteocyte: an endocrine cell . . . and more. Endocr Rev. 2013;34(5):658-90.

68. Pathak JL, et al. Systemic inflammation affects human osteocytespecific protein and cytokine expression. Calcif Tissue Int. 2016;98(6):596-608.

69. Brolese E, Buser D, Kuchler U, Schaller B, Gruber R. Human bone chips release of sclerostin and FGF-23 into the culture medium: an in vitro pilot study. Clin Oral Implants Res. 2015;26(10): 1211-4.

70. Ben-awadh AN, et al. Parathyroid hormone receptor signaling induces bone resorption in the adult skeleton by directly regulating the RANKL gene in osteocytes. Endocrinology. 2014;155(8): 2797-809.

71. Kassem A, Lindholm C, Lerner UH. Toll-Like receptor 2 stimulation of osteoblasts mediates Staphylococcus aureus induced bone resorption and osteoclastogenesis through enhanced RANKL. PLoS ONE. 2016;11(6).

72. Ferrarini M, et al. Ex-vivo dynamic 3-D culture of human tissues in the RCCS ${ }^{\mathrm{TM}}$ bioreactor allows the study of multiple myeloma biology and response to therapy. PLoS ONE. 2013;8(8).

73. Sloan AJ, et al. A novel ex vivo culture model for inflammatory bone destruction. J Dent Res. Aug. 2013;92(8):728-34.

74. Curtin P, Youm H, Salih E. Three-dimensional cancer-bone metastasis model using ex-vivo co-cultures of live calvarial bones and cancer cells. Biomaterials. 2012;33(4):1065-78.

75. Okubo N, et al. Prolonged bioluminescence monitoring in mouse ex vivo bone culture revealed persistent circadian rhythms in articular cartilages and growth plates. PLoS ONE. 2013;8(11).

76. Chagin AS, Karimian E, Sundström K, Eriksson E, Sävendahl L. Catch-up growth after dexamethasone withdrawal occurs in cultured postnatal rat metatarsal bones. J Endocrinol. 2010;204(1): 21-9.

77. Ben-Ami Y, von der Mark K, Franzen A, de Bernard B, Lunzzi GC, Silbermann M. Transformation of fetal secondary cartilage into embryonic bone in organ cultures of human mandibular condyles. Cell Tissue Res. 1993;271(2):317-22.

78. Mohammad KS, Chirgwin JM, Guise TA. Assessing new bone formation in neonatal calvarial organ cultures. Methods Mol Biol. 2008;455:37-50.

79. Srinivasaiah $\mathrm{S}$, et al. A $300 \mu \mathrm{m}$ organotypic bone slice culture model for temporal investigation of endochondral osteogenesis. Tissue Engineering - Part C: Methods. 2019;25(4):197-212.

80. Stoddart MJ, Furlong PI, Simpson A, Davies CM, Richards RG. A comparison of non-radioactive methods for assessing viability in ex vivo cultured cancellous bone: technical note. European Cells and Materials. 2006;12:16-25.

81. Gabriele Sommer N, Hahn D, Okutan B, Marek R, Weinberg AM. Animal models in orthopedic research: the proper animal model to answer fundamental questions on bone healing depending on pathology and implant material. Animal Models in Medicine and Biology. 2020.
82. Abubakar AA, Noordin MM, Azmi TI, Kaka U, Loqman MY. The use of rats and mice as animal models in ex vivo bone growth and development studies. Bone and Joint Research. 2016;5(12): 610-8.

83. Osyczka AM, Diefenderfer DL, Bhargave G, Leboy PS. Different effects of BMP-2 on marrow stromal cells from human and rat bone. Cells Tissues Organs. 2004;176(1-3):109-19.

84. Kogawa M, et al. Sclerostin regulates release of bone mineral by osteocytes by induction of carbonic anhydrase 2. J Bone Miner Res. 2013;28(12):2436-48.

85. Kuttenberger J, Polska E, Schaefer BM. A novel threedimensional bone chip organ culture. Clin Oral Investig. 2013;17(6):1547-55.

86. Klüter T, et al. An Ex Vivo bone defect model to evaluate bone substitutes and associated bone regeneration processes. Tissue Engineering Part C: Methods. 2020;26(1):56-65.

87. Walker LM, Preston MR, Magnay JL, Thomas PBM, el Haj AJ. Nicotinic regulation of $\mathrm{c}$-fos and osteopontin expression in human-derived osteoblast-like cells and human trabecular bone organ culture. Bone. 2001;28(6):603-8.

88. Osta B, et al. Differential effects of IL-17A and TNF- $\alpha$ on osteoblastic differentiation of isolated synoviocytes and on bone explants from arthritis patients. Frontiers in Immunology. 2015;6(115).

89. Chabaud M, Lubberts E, Joosten L, van den Berg W, Miossec P. IL-17 derived from juxta-articular bone and synovium contributes to joint degradation in rheumatoid arthritis. Arthritis Res. 2001;3(3):168-77.

90. Amanatullah DF, et al. Local estrogen axis in the human bone microenvironment regulates estrogen receptor-positive breast cancer cells. Breast Cancer Research. 2017;19(1):121.

91. Templeton ZS, Bachmann MH, Alluri RV, Maloney WJ, Contag $\mathrm{CH}$, King BL. Methods for culturing human femur tissue explants to study breast cancer cell colonization of the metastatic niche. Journal of Visualized Experiments. 2015;(97).

92. Holen I, Nutter F, Wilkinson JM, Evans CA, Avgoustou P, Ottewell PD. Human breast cancer bone metastasis in vitro and in vivo: a novel 3D model system for studies of tumour cell-bone cell interactions. Clin Exp Metastasis. 2015;32(7):689-702.

93. Salamanna F, et al. An in vitro $3 \mathrm{D}$ bone metastasis model by using a human bone tissue culture and human sex-related cancer cells. Oncotarget. 2016;7(47):76966-83.

94. Madsen SH, et al. Characterization of an ex vivo femoral head model assessed by markers of bone and cartilage turnover. Cartilage. 2011;2(3):265-78.

95. Maglio M, Tschon M, Sicuro L, Lolli R, Fini M. Osteochondral tissue cultures: between limits and sparks, the next step for advanced in vitro models. J Cell Physiol. 2019;234(5):5420-35.

96. Geurts J, Jurić D, Müller M, Schären S, Netzer C. Novel ex vivo human osteochondral explant model of knee and spine osteoarthritis enables assessment of inflammatory and drug treatment responses. International Journal of Molecular Sciences. 2018;19(5).

97. de Vries-van Melle ML, Mandl EW, Kops N, Koevoet WJLM, Verhaar JAN, van Osch GJVM. An Osteochondral culture model to study mechanisms involved in articular cartilage repair. Tissue Engineering Part C: Methods. 2012;18(1):45-53.

98. Duchi S, et al. Protocols for culturing and imaging a human ex vivo osteochondral model for cartilage biomanufacturing applications. Materials. 2019;12(4).

99. Schwab A, et al. Ex vivo culture platform for assessment of cartilage repair treatment strategies. ALTEX. 2017;34(2):267-77.

100. Schaller $\mathrm{S}$, et al. In vitro, ex vivo, and in vivo methodological approaches for studying therapeutic targets of osteoporosis and degenerative joint diseases: how biomarkers can assist? Assay and Drug Development Technologies. 2005;3(5):553-80. 
101. Smith SY, Varela A, Jolette J. Nonhuman primate models of osteoporosis. In: Duqui G, Watanabe K, editors. Osteoporosis Research - Animal Models. London, UK: Springer-Verlag; 2011. p. 135-57.

102. Delgado-Calle J, et al. MMP14 is a novel target of PTH signaling in osteocytes that controls resorption by regulating soluble RANKL production. FASEB J. 2018;32(5):2878-90.

103. $\mathrm{Kim} \mathrm{H}$, et al. Small molecule inhibitors of the Dishevelled-CXXC 5 interaction are new drug candidates for bone anabolic osteoporosis therapy. EMBO Molecular Medicine. 2016;8(4):375-87.

104. Nakajima K, et al. Enhancement of bone formation ex vivo and in vivo by a helioxanthin-derivative. Biochem Biophys Res Commun. 2010;395(4):502-8.

105. Smith EL, et al. Evaluation of skeletal tissue repair, part 1: assessment of novel growth-factor-releasing hydrogels in an ex vivo chick femur defect model. Acta Biomater. 2014;10(10):4186-96.

106. Barros J, Ferraz MP, Azeredo J, Fernandes MH, Gomes PS, Monteiro FJ. Alginate-nanohydroxyapatite hydrogel system: optimizing the formulation for enhanced bone regeneration. Materials Science and Engineering C. 2019;105.

107. Yang XB, et al. Human osteoprogenitor bone formation using encapsulated bone morphogenetic protein 2 in porous polymer scaffolds. Tissue Eng. 2004;10(7-8):1037-45.

108. Smith EL, et al. Evaluation of skeletal tissue repair, part 2: enhancement of skeletal tissue repair through dual-growth-factorreleasing hydrogels within an ex vivo chick femur defect model. Acta Biomater. 2014;10(10):4197-205.

109. Rahman S, Atkins GJ, Findlay DM, Losic D. Nanoengineered drug releasing aluminium wire implants: a model study for localized bone therapy. J Mater Chem B. 2015;3:3288-96.

110. Fernandes G, Wang C, Yuan X, Liu Z, Dziak R, Yang S. Combination of controlled release platelet-rich plasma alginate beads and bone morphogenetic protein- 2 genetically modified mesenchymal stem cells for bone regeneration. J Periodontol. 2016;87(4):470-80.

111. Moreno-Jiménez I, Lanham SA, Kanczler JM, Hulsart-Billstrom G, Evans ND, Oreffo ROC. Remodelling of human bone on the chorioallantoic membrane of the chicken egg: De novo bone formation and resorption. J Tissue Eng Regen Med. 2018;12(8):1877-90.

112. Liu J, Czernick D, Lin SC, Alasmari A, Serge D, Salih E. Novel bioactivity of phosvitin in connective tissue and bone organogenesis revealed by live calvarial bone organ culture models. Dev Biol. Sep. 2013;381(1):256-75.

113. Almehmadi A, et al. VWC2 increases bone formation through inhibiting Activin signaling. Calcif Tissue Int. 2018;103(6):663-74.

114. Kim H, et al. Extracellular S100A4 negatively regulates osteoblast function by activating the NF-KB pathway. BMB Rep. 2017;50(2): 97-102.

115. Abdallah BM, Jensen CH, Gutierrez G, Leslie RGQ, Jensen TG, Kassem M. Regulation of human skeletal stem cells differentiation by Dlk1/Pref-1. J Bone Miner Res. May 2004;19(5):841-52.

116. Rufo A, et al. Mechanisms inducing low bone density in Duchenne muscular dystrophy in mice and humans. J Bone Miner Res. 2011;26(8):1891-903.

117. Yamazaki M, et al. Interleukin-1-induced acute bone resorption facilitates the secretion of fibroblast growth factor 23 into the circulation. J Bone Miner Metab. 2015;33(3):342-54.

118. Liu Y, et al. The orphan receptor tyrosine kinase Ror2 promotes osteoblast differentiation and enhances ex vivo bone formation. Mol Endocrinol. 2007;21(2):376-87.

119. Ishikawa M, Iwamoto T, Fukumoto S, Yamada Y. Pannexin 3 inhibits proliferation of osteoprogenitor cells by regulating Wnt and p21 signaling. J Biol Chem. 2014;289(5):2839-51.

120. Wang F, et al. Peptides from Antarctic krill (Euphausia superba) ameliorate senile osteoporosis via activating osteogenesis related
BMP2/Smads and Wnt/ $\beta$-catenin pathway. Journal of Food Biochemistry. 2017;41(4):e12381.

121. Kanczler JM, Millar TM, Bodamyali T, Blake DR, Stevens CR. Xanthine oxidase mediates cytokine-induced, but not hormoneinduced bone resorption. Free Radic Res. 2003;37(2):179-87.

122. Jaha H, et al. N-terminal dentin Sialoprotein fragment induces type I collagen production and upregulates dentinogenesis marker expression in osteoblasts. Biochemistry and Biophysics Reports. 2016;6:190-6.

123. Bodine PVN, et al. A small molecule inhibitor of the Wnt antagonist secreted frizzled-related protein-1 stimulates bone formation. Bone. 2009;44(6):1063-8.

124. Laitala-Leinonen T, Väänänen HK. Decreased bone resorption, osteoclast differentiation, and expression of vacuolar $\mathrm{H}+-$ ATPase in antisense DNA-treated mouse metacarpal and calvaria cultures ex vivo. Antisense and Nucleic Acid Drug Development. 1999;9(2):155-69.

125. Rao SR, Edwards CM, Edwards JR. Modeling the human bonetumor niche: reducing and replacing the need for animal data. JBMR Plus. 2020;(4, 4)

126. Cuero CN, Iduarte B, Juárez P. Measuring bone remodeling and recreating the tumor-bone microenvironment using calvaria coculture and histomorphometry. Journal of visualized experiments : JoVE. 2020;(157):e59028.

127. Salih E. Ex-vivo model systems of cancer-bone cell interactions. Methods Mol Biol. 2019;1914:217-40.

128. Alasmari A, Lin SC, Dibart S, Salih E. Bone microenvironmentmediated resistance of cancer cells to bisphosphonates and impact on bone osteocytes/stem cells. Clin Exp Metastasis. 2016;33(6): 563-88.

129. Delgado-Calle J, et al. Aplidin (plitidepsin) is a novel antimyeloma agent with potent anti-resorptive activity mediated by direct effects on osteoclasts. Oncotarget. 2019;10(28):2709-21.

130. Marino S, Bishop RT, Mollat P, Idris AI. Pharmacological inhibition of the skeletal IKK $\beta$ reduces breast cancer-induced osteolysis. Calcif Tissue Int. 2018;103(2):206-16.

131. Marino S, Bishop RT, Carrasco G, Logan JG, Li B, Idris AI. Pharmacological inhibition of NFKB reduces prostate cancer related osteoclastogenesis in vitro and osteolysis ex vivo. Calcif Tissue Int. 2019;105(2):193-204.

132. Watanabe K, et al. The MET/vascular endothelial growth factor receptor (VEGFR)-targeted tyrosine kinase inhibitor also attenuates FMS-dependent osteoclast differentiation and bone destruction induced by prostate cancer. J Biol Chem. 2016;291(40): 20891-9.

133. Frantzias J, et al. Hydrogen sulphide-releasing diclofenac derivatives inhibit breast cancer-induced osteoclastogenesis in vitro and prevent osteolysis ex vivo. Br J Pharmacol. 2012;165(6):1914-25.

134. Wijenayaka AR, et al. 1 $\alpha, 25$-dihydroxyvitamin D3 stimulates human SOST gene expression and sclerostin secretion. Mol Cell Endocrinol. 2015;413:157-67.

135. Elson KM, et al. Non-destructive monitoring of viability in an ex vivo organ culture model of osteochondral tissue. European Cells and Materials. 2015;29:356-69.

136. Roach HI. Long-term organ culture of embryonic chick femora: a system for investigating bone and cartilage formation at an intermediate level of organization. J Bone Miner Res. 1990;5(1):85-100.

137. Pitsillides AA, Rawlinson SCF. Using cell and organ culture models to analyze responses of bone cells to mechanical stimulation. Methods Mol Biol. 2012;816:593-619.

138. van der Valk J, et al. Fetal bovine serum (FBS): past - present future. ALTEX. 2018;35(1):99-118.

139. Schulte FA, Lambers FM, Webster DJ, Kuhn G, Müller R. In vivo validation of a computational bone adaptation model using openloop control and time-lapsed micro-computed tomography. Bone. 2011;49(6):1166-72. 
140. Schulte FA, Lambers FM, Kuhn G, Müller R. In vivo microcomputed tomography allows direct three-dimensional quantification of both bone formation and bone resorption parameters using time-lapsed imaging. Bone. 2011;48(3):433-42.

141. Park SY, et al. The evaluation of the correlation between histomorphometric analysis and micro-computed tomography analysis in AdBMP-2 induced bone regeneration in rat calvarial defects. Journal of Periodontal and Implant Science. 2011;41(5):218-26.
142. Yeh SCA, Wilk K, Lin CP, Intini G. In vivo 3D histomorphometry quantifies bone apposition and skeletal progenitor cell differentiation. Sci Rep. 2018;8(1):1-10.

Publisher's Note Springer Nature remains neutral with regard to jurisdictional claims in published maps and institutional affiliations. 